\title{
The Psychological Well-Being of Single Mothers with School age Children : An Exploratory Study
}

\author{
Dr. D. D. K. S. Karunanayake ${ }^{1}$, Mohamed Nazeer Aysha ${ }^{2}$, N. D. U. Vimukthi ${ }^{3}$ \\ ${ }^{1} \mathrm{Ph} . \mathrm{D}$. (Purdue), Senior Lecturer in Psychology, Department of Psychology, \\ University of Peradeniya, Sri Lanka, \\ ${ }^{2}$ Department of Psychology, University of Peradeniya, Sri Lanka \\ ${ }^{3}$ BA (Hons), Psychology, Department of Psychology, University of Peradeniya,
}

Sri Lanka

Article Info
Volume 8, Issue 1
Page Number: 16-37
Publication Issue :
January-February-2021

Article History

Accepted : 01 Jan 2021

Published : 06 Jan 2021

\section{ABSTRACT}

The significance of family structure on the well-being of family members is a major concept to be discussed in contemporary society. There is an impact on the overall well-being of the families due to the lack of major relationships. Hence, the major consequences that lead to the sole responsibility of children to mothers differ among locality, culture, language, etc. This study explores the psychological well-being of single mothers in relation to their role in the family, the major concepts that impact the psychological well-being, the impact of parenting, and the modes in which the single mothers cope up with the challenges they encounter. This is a qualitative (exploratory) study conducted with nine participants chosen from a convenient method of sampling located in the Kandy District of the Central Province, Sri Lanka. The sample of the research includes three each of widowed, divorced, and separated mothers. The data is thematically analyzed based on the challenges, the economic well-being, and relationship with the family and the society, the ideologies about the current status, society's stereotypes, autonomy, the satisfaction to the present life, and their future expectations. The results of the study demonstrated that the responsibility of children, the financial crisis, confronting the society, and lack of emotional dependence to be the major challenges of single motherhood. It further stated that most of them had a strong relationship with their children and the family in comparison to the society, they found themselves to be often treated by stereotypes, and that they preferred autonomy in women. The findings of the study demonstrate that the Government should help them with self-employment, assist in the studies of their children, and conduct certain awareness programs to enhance their lives.

Keywords : Single Mothers, School-aged Children, Psychological Well-being, Challenges 


\section{INTRODUCTION}

The major objective of this study is to explore the lifestyle of single mothers and to examine the psychological well-being in accordance with the challenges encountered. The primary motive of the study is based on the psychological well-being which is affected by the contributory causes of economic, socio-cultural, and physical factors. This section will provide an account of the background, the significance, objectives as well as the outline of the study. A family is considered to be the basic social unit that molds human beings as distinct individuals (Hossain \& Ali, 2014). The so-called 'normal' family is comprised of a father, mother, and children, which is identified as the miniature mode whereas an extended family includes grandparents, other related families, etc. The structure of a family is regarded as significant since it is the roles executed by each of the family members that contribute to the living (Rosenthal \& Marshall, 1986). Since the ancient era, men and women were assigned a part to perform as contributions to family well-being. Moreover, the concept of child-rearing is a shared responsibility of both parents although mothers are normally looked at as the primary caretakers. It is the responsibility of the father to assist the family financially, provide shelter, and assure safety for the family members.

The regular structure of a family is put into many changes along with the evolution of humanity. The concept of single-parenthood is a rarely spoken term years ago, although it has adjoined as one of the types of family and parenthood in contemporary society. Individuality, the need for independence, feminism, and masculism can be viewed as the major cause for the emergence of single-parent families (Young, 1995). Single-parent families are the unit of a family where a sole parent who is either the mother or father is responsible for child-rearing (William et. al., 2009).
Although the concept of single fatherhood is present in society, single mothers are the overwhelming majority of single parents.

Single motherhood is identified as a significant role of single-parenting which is more common in Western countries compared to Asian countries. Hence, with the passage of time, the convictions in relation to single-mother families have changed enormously as an increased growth is evident in Asian countries. Along with the sprouts of many views either being influenced by western countries or developed on its own, single motherhood is a concept that is spreading widely in the contemporary Sri Lankan context.

The primary consequences of single motherhood are divorce, death of a spouse, and abandonment by the partner. Ensuring the sole responsibility of the family is more or less a problematic factor compared to the dual-parent families, hence, the challenges encountered by single mothers. Although financial issues are considered as the major concern, the social well-being of single-parents is an unspoken predominant factor in society.

The stereotypes which are believed and followed by the society is a major element that impacts the lives of single mothers in the Sri Lankan community even though the concept seems to be somewhat accepted. Hence, the social aspects of single mothers are as important as the financial issues encountered by single mothers in examining their overall psychological well-being.

\section{LITERATURE REVIEW}

Family- Family is the basic social unit that consists of one or two parents with one or more children. According to the 'normal' family, a mother is in 
charge of the household and children's maintenance while a father is responsible for economic as well as defending factors. According to Smolka (2001), the customary manner of defining a family was as that of a set of individuals connected via blood, marriage, or adoption yet has evolved towards more factors such as homosexual families, heterosexual families, singleparent households, blended families, and families with extended kin (Smolka, 2001).

Single Mother- A single mother is the parent of one or more children with the absence of the spouse generally due to separation, divorce, or death (Biblarz \& Gottainer, 2000). According to Goldscheider, Scott, Lilja \& Bronte-Tinkew, 2015, if the single-parent is the mother, she is engulfed with the responsibilities of a mother as well as a father. After the loss of the partner, a single mother becomes the head of the family and takes charge of the obligations that were generally entitled to a father for economic as well as psychological needs. According to a study, single mothers encountered many negative incidents for both personal as well as economic well-being (Williams \& Compas, 1988). Most of the single-parent families in China were headed by single mothers and are the fastest-growing families living in poverty $(\mathrm{Li}$, 2020).

Challenges encountered by Single Mothers- Parenting has its own challenges of responsibilities or obligations that are entrusted to them via culture, family, religion, environment, etc. Household income has a positive correlation with the quality of life while the social condition of being a woman was considered to be a major challenge. Financial income was directly connected to the social condition of single mothers (Hernández et al., 2009). Based on a study conducted by Lee, Law, and Tam (1999), singleparents in comparison to dual parents were under financial strains and lack support to maintain childcare responsibilities. The single parents who worked had the additional burden of managing time efficiently to maximize meeting the needs of their children (Lee, Law \& Tam, 1999). Another research states that they encountered residential problems and issues about the education of the children in addition to the financial and childcare responsibilities (Gotea \& Busuioc, 2016). A study conducted in America showed financial needs, time management and childcare responsibilities as the major challenges encountered by single mothers (Quinn \& Allen, 1987). Moreover, most of them felt that they were regarded by society as individuals who had failed in their marital life which was a major challenge in surviving in society. According to William (1975), the major challenge encountered by American single women was to deal with poverty. Additional challenges, which were considered the generic aspects of challenges were role conflicts, role shifts, dealing with public attitudes, and coping with emotional deprivation (William, 1975). Handling the responsibilities of children, managing social support and financial conflicts as well as dealing with the physical and emotional stress were regarded as the major queries of single mothers (Stack \& Meredith, 2018). A study conducted among the single-parent mothers in rural northeastern Vermont demonstrated that the major challenges encountered by them were problems in relation to personal health, financial struggles as well as issues in family (Williams \& Compas, 1988). The overall factors demonstrated as the principal challenges encountered by the single mothers were time management, financial struggles, dealing with society, managing childcare responsibilities as well as problems in relation to mental health.

Psychological Well-being of Single Mothers- A study conducted by Samuels-Dennis (2007) shows that single mothers, specifically with social assistance, generally tend to report more depressive symptoms than common individuals. A cross-sectional survey design with mailed questionnaires was distributed among ninety-six single mothers where half of them have had an income via employment while the rest 
with assistance tend to experience a considerably greater amount of stressful incidents during the previous two years than the employed single mothers. Employment had a negative relationship with the depressive symptoms where it was moderated by the coping strategies that were adopted. There was an adverse relationship between employment and stressful life events and it depends on the coping strategies of single mothers (Samuels-Dennis, 2007). A research was conducted to examine the psychological well-being and poverty among the low-income single mothers and the financially unstable mothers who reside with their partners (Hammans, 2010). The outcome of the research concluded that single mothers living in poverty had a high risk of having psychological issues than partnered mothers living in poverty.

A study by Mulroy and Lane (1992) states that permanent residency was a predominant cause of stress among the single mothers since she was expected to handle the sole responsibility of a caretaker, provider and act as a shelter to the children and herself. Lack of a stable dwelling was considered to be an added cause of burden along with the other challenges of handling society, childcare responsibilities, and financial crisis to a solitary mother. Another study examined the impact of dwelling in either rural or urban areas on the psychological well-being of single mothers by Ahmad et al., (2015). The results of the analysis concluded that there was no considerable disparity in the level of psychological well-being depending on the area of dwellings or culture but the factor of low monthly income impacted the psychological well-being. SegalEngelchin \& Wozner, (2005) indicated single mothers on the psychological, social, physical, and cultural basis which contributes to the quality of life. Besides the economic crisis and the absence of a partner, single mothers by choice had a comparatively high quality of life than the married mothers. There was a lack of indicative differences among single mothers by choice and divorced mothers. Abd Ghani et al., (2015) did research aimed at exploring the relationship between the belief system and emotional well-being of single mothers. The results of the study indicated a significant relationship between the two variables, the belief system of single mothers and their emotional well-being and vice versa. In a study conducted by Ifcher and Zarghamee (2014) the single mothers were less happy than the partnered mothers due to the fact that single mothers tend to exhibit being 'not too happy' and less likely to exhibit being 'very happy'. Another research indicated depression, income, and the number of children as the predictors of the quality of life and that the women from singleparent families tend to have a lower quality of life, lower-income, and greater depression in comparison to the women from partnered families (Hernández et al., 2009). A study by Zekeri (2020) was held to identify the prevalence of food insecurity among single mothers and its connection to the cause of depression. The results of the study indicated that among the sample of three hundred single mothers household food insecurity was positively correlated with depression. Weldegabreal (2014) conducted research on the experience of single mothers in bringing up their children. The results of the study indicated that single mothers dealt with financial struggles to cope with the basic needs of the children while facing the psychological challenges of helplessness, hopelessness, and loneliness. It further stated that the single mothers encountered psychological issues like anxiety and stress due to inadequate resources and relationship developmental issues with the children as a result of their inability to fulfill their needs. Tucker \& Kelley (2009) conducted another research with the objective of demonstrating the association between social support and life events stress in fifty single active-duty enlisted United States Navy mothers. The survey concluded that the friends and the aids at the workplace and negative life events impact the psychological health of single active-duty 
enlisted Navy mothers. A significant study was conducted in Kenya with the objectives of identifying the major causes of single-parenting, psychological challenges of single-parenting, social challenges of single-parenting, and mediators to handle the psychosocial challenges in single-parenting (Wangechi Watuthu et al., 2017). The results of the study indicated that most of the single-parents encountered psychological challenges that prejudicially affected their parenting, social life as well as mental well-being. The psychological challenges that they encountered were emotional stress, loneliness, low self-esteem, depression, isolation fear, anxiety, and resentment. The social challenges that they faced were discrimination, task overload, stigmatization, insecurity, and stereotyping. Further, most of the single-parents got addicted to alcohol as a coping mechanism to overcome these challenges. Furthermore, Subramaniam et al. (2014), conducted a study to demonstrate the prevalence of depression, mood disorders, and anxiety disorders among the multiethnic Asian society in Singapore. The results suggested that single mothers had a considerably higher probability of having mood disorders than partnered mothers.

\section{METHODOLOGY}

The study employed nine single mothers chosen under three categories who were responsible for either one or more schooling children located in the Kandy District of the Central Province, Sri Lanka. Three of them were single mothers due to divorce, three due to the demise of their spouse, and another three due to being abandoned by the partner. participants were of various social, economic, and family backgrounds. The study was implemented as a qualitative research design with semi-structured interviews under a set of generally guided questions to gather information in relation to the concepts of the analysis. The interviews were conducted at the dwellings of the participants with a set of guided questions. The conversations were recorded with their consent using a mobile phone. Each of them was contacted privately to gain consent and to allocate a convenient time to conduct the interviews. During the meetup, each of them was provided with a consent form and further clarifications about the privacy issues were verbally discussed. The sessions lasted between thirty minutes to an hour depending on the length of the answers provided and the extent to which the required aspects of information were gained. By the end of the interviews, each of them was provided with the contact details of the researcher in case of a need for further clarifications.

\section{RESULTS}

The analysis of participant information yielded ten main sections and some sub-sections. They were, Demographical data (details of their marital status, age, children, Educational Qualification and Occupation, and the mode of dwelling), Major challengers (the responsibility of children, financial crisis, confronting the society, lack of emotional dependence), Economic well-being of the family, The prior and post relationship of single motherhood (children, maternal and paternal family, the family of in-laws, friends, neighbors), The difference in comparison to the status prior and post single motherhood, Their perspective on the society's views and stereotypes about single mothers, Single mother's view on how she is regarded, The satisfaction of their present life, Ideologies about autonomy in women (prior and past single motherhood) and Future expectations of single mothers.

\section{Demographical data}

Marital Status- The nine participants of the study were assigned with an identity based on their marital status: Single mothers due to the demise of the spouse - A1, A2, A3; Single mothers as a result of divorce - 
B1, B2, B3; and Single mothers abandoned by the partner or separated - C1, C2, and C3.

Age- Most of the participants were in their thirties while two were in their early forties. Most of the mothers have got married in their early twenties, one during the late twenties and another at the onset of thirty years.

Children- Among the three widowed mothers, two of them had more than one female child while the other had one male child. It is mandatory to note that each of the three divorced mothers had only one female child. Further, all separated mothers had more than one child of both genders.

Educational Qualification and Occupation- All widowed mothers and two of the divorced mothers have completed their Advanced level studies while one of the divorced mothers had completed the Ordinary Level studies. It is significant to note that all three separated mothers had a qualification lesser than the Ordinary level studies. On the aspect of occupation, six of the single mothers engage in selfemployment such as sewing at home or selling homemade food, while the others do not engage in any type of occupation.

Mode of Dwelling- Most of the single mothers live in their own house with their parents and children while a few live with their children alone. Only two of the single mothers live in rented houses and the rest own their home.

\section{Major Challenges}

The Responsibility of Children- According to the information provided by the participants, one of the major challenges that most mothers encounter was the responsibility of their children. (Quotes of the participants have been marked by their assigned anonymous identity)

"Taking complete responsibility of my children is the major challenge for me." (C1)

"I found the responsibility of handling the children alone as the major challenge." (C3)
Moreover, there is a disparity between the single mother's responsibilities to the children based on the children's gender. The results demonstrated that almost all of the mothers who had female children found it to be an immense responsibility to protect their daughters and survive in society.

"The most important challenge is protecting my daughters which I find difficult to provide as a mother." (Participant A1)

"The most important issue is the absence of a guardian. I have my father and my two younger brothers. One of them is abroad and the other one is married and has four kids, so I cannot depend on my brothers. My father is quite old. So I am in a situation of doing my children's and my work all alone." (Participant A2)

The major concern among a few single mothers with male children seemed to be the absence of a strict parent who can control the behavior of their son.

"My son is a late teen and I find it difficult to manage him without a father. I'm worried about his friends and acquaintances. He creates problems at school and is seen by the school counselor" (Participant C1)

Another predominant aspect from the analysis is that most mothers encounter difficulty in fulfilling the loss of a father to the child (Karunanayake \& Vimukthi, 2020). This is more complicated especially when the husband had died at an age when the child could understand the loss.

"My major challenge is to take care of my son. As a boy, he was so attached to his father. He was so possessive that he didn't prefer going to school with anyone in the three-wheeler with his father. He used to talk to him all the way to school and back. Now I can't fulfill his loss." (Participant A3)

There was one single mother who was divorced who demonstrated that she never had to take complete responsibility for the child and that it hasn't been a challenge.

"I had my mother to support me. She looked after my daughter. I had nothing as a challenge. I was happy 
after getting divorced. There is always a way" (Participant B3)

Financial Crisis- According to the results of the discussion, almost all of the single mothers acknowledged the maintenance of the financial wellbeing of the family to be another major challenge that they encounter. Some of them stated that it was difficult when it comes to the resources that the children need.

"And I lack the ability to provide for them what they need." (Participant A1)

"Besides managing the child, the economical difficulties are the major issues. And I try my best to make her not feel inferior compared to the others in providing resources." (Participant B2) Moreover, a significant factor derived from the result is that few mothers who live in a rented house found it to be a major concern and a challenge to manage the rent.

"And I live in a rented house which is not a permanent solution." (Participant A1)

"We don't have an own house. We have to leave the house when the owners want. I feel insecure." (Participant C2)

Confronting the Society- One of the crucial factors that some single mothers discussed was the challenge of confronting society. Most of them stated that their work was often interrupted with the very concern of how society will look upon them.

"And society always blame us. Society does not inquire from the women what their partners do, but we are always at a risk of being blamed. Even the ones who are close to us also judge me often. I become so upset and hurt due to this." (Participant A2) Lack of Emotional Dependence- Based on the discussion, many among the single mothers' major challenge was to maintain their emotional stability due to the lack of an individual to share their emotions. The crucial factor seemed to be that all the other challenges contribute towards forming difficulty in maintaining their emotions. The above condition was prevalent especially among the widowed mothers whose loss of the partner was abrupt. Further, they stated that it becomes unbearable as they had to deal with the problems and bear the pain and sorrows by themselves.

"Lack of emotional support is the overall challenge that I encounter. People think that once we get enough money to lead a life and that there are other people to look after us, that we are leading a happy life. Which is not true." (Participant A2)

However, there was one divorced mother who disagreed with the general view of all the other single mothers.

"I had the courage to tell everyone who blamed me for getting divorced not to point me out. I was always strong. I had never cried. I haven't worried. I always think about the next step." (Participant B3)

\section{Economic Well-being of the Family}

Based on the discussion, the results emphasized that almost all of the single mother's struggle to maintain the economic well-being of the family. Moreover, a certain distinction can be noticed among each category of single mothers in relation to economic well-being. Most of the widowed mothers were aided by their family and they emphasized the fact that they were grateful for the family's support. Hence, a major concern for them seemed to be that they should reduce the amount of economic dependency on the family.

"The economic issues are the major concerns in bringing up my children. Because I can be a hindrance to my parents. I don't have the capacity to engage in proper work." (Participant A1)

"I have economic problems since it is my mother who looks after me." (Participant A3)

There seemed to be a difference among the divorced mothers in accepting the child maintenance payments. The majority of them who had filed divorce themselves had refused to receive the money. They were pretty certain of the fact that they should never rely upon the father of their children. One mother 
also was of the opinion that she prefers her daughter to be schooled in a sigle sex school wants independence in choosing a school for her daughter thereby declining child support (Karunanayake, Amarathunga \& Vimukthi, 2020).

"I don't seek help from anyone. There are many organizations available to help children like mine. But I would like to mention this here, I have not sought any help from others for my daughter's education in a girls school which I believe is better for her. All of her expenses concerning her studies are from my own earnings because I don't want any influence about my choice." (Participant B2)

However, one of the participants reported that she obtains a child-maintenance from the child's father. She tends to manage her expenses with that along with aids provided by her other family members.

"My daughter's father provides 7000 rupees per month for her expenses. My family members help me and my mother financially." (Participant B1)

Among the separated mothers two of them were dependent upon the husband's income. Hence, all of them reported having difficulty in managing the expenses of their families.

"I manage the financial needs via the money sent by my husband. He sends 15000 per month for the three children. They are going to a government school. But I have to spend 3000 for their transportation to school. For religious school, I have to spend about 2000 per month. So I manage them with much difficulty." (Participant C1)

However, most of the single mothers had to struggle in attaining this amount of money from the father of these children. According to their view:

"Sometimes he doesn't deposit the money on time. So I have to go to the courts to get them." (Participant C2)

\section{The prior-post relationship of Single Motherhood} Children- According to the discussion, all three widowed mothers stated that they spent a happy and satisfactory family life with their partners. And all of their children have spent a life with both father and mother for some time in their life. Therefore, single mothers have experienced greater difficulty in maintaining a positive relationship with the children and to provide dual-parent care and affection. But they agreed that their relationship with the children became stronger after becoming a single mother.

"My time spent with them and the affection that I've shown them was comparatively less in the presence of my husband. But after his demise, I was added with the responsibility of showing them the dual care of father's love. I am supposed to be their advisor as well as their guide which was a huge load for me. I found that our relationship became stronger." (Participant A2)

Contrary to the above view, the divorced mothers demonstrated that they lived a lesser time as partnered parents and that the children have little or no acquaintance with their father (Karunanayake, Bambarawana, and Vimukthi, 2020). Hence, they agreed that they always had a positive relationship before the divorce and that after the divorce it became stronger.

"My husband stayed abroad most of the time. He came to the country when my child was just one-anda-half-year-old. And he was with me and my daughter for about three months. My bonding with my daughter is always high. I felt it became stronger when I came to my home after being separated. Now she is in a situation to talk to me about anything she wants." (Participant B2).

The separated mothers stated that they don't identify any difference in the relationship with their children. Two of them live wanted the husband to returns to them. One of them stated that they tend to display their anger towards their husbands to their children.

"I see a lot of difference in our life. But I don't find a difference in the relationship with my children. But after he left and if I show my frustration to my children, they tell me "why are you showing your anger to us?'. Therefore, I try my best not to show my 
anger to them or they might hate me too." (Participant C3)

A predominant factor revealed during the conversation with a divorced mother was that she felt her daughter had become an individual that she wanted her to be after the divorce.

"My daughter will not be the person who she is now if we had remained at my in-laws still. Their behaviors are not acceptable. And my husband used to take drugs. My daughter's mentality will be definitely affected by this" (Participant B2)

It was evident that all of these mothers' major concern was to maintain a positive relationship with their children as a father as well as a mother.

Maternal and Paternal Family- According to the discussion, all three widowed mothers demonstrated that they had been in a positive relationship with their families prior to single motherhood and that it continued to be the same after the demise of their partner. In addition, they stated that the relationship was stronger at present as it was the family whom they were depending upon. All of them live with their parents although one stated that she was with the in-laws' for some time after the husband passed away. Further, it was identified that they had never been completely dependent on their families during the husband's presence.

"I had a good relationship with them before my husband's demise and it is continuing to be the same. They never rejected me and still supporting to make me and my children survive. And I pray to God to have all of them to remain the same throughout my life." (Participant A1)

Two of the divorced mothers agreed that they had been on good terms with their family before and after marriage. And that it continued to be the same after getting divorced too. The other divorced mother stated that she could not be on good terms after marriage since she was worried about the abuse of her husband. She further mentioned that although the family supported her, they did it for some selfish motives.

"My sisters made me look after their kids after I got divorced. And a marriage proposal they brought for me broke with which my slavery to them also broke. I didn't know I was being a slave. I did whatever they told me because I love them. I was released from it only after two or three years of my mother's demise. I felt I was controlled by them. Now I live independently." (Participant B3)

However, the results of the discussion with the separated mothers were quite a contrast to the other single mothers. Although two of them agreed upon the fact of remaining in a positive relationship with their family, they had seldom been dependent upon them. One of them stated to be on bad terms with the family after marriage due to the fact of being married without the family's consent. Hence, she admitted that she rarely depends on her family's support.

"I have sort of the same relationship with them. My sisters even ask me to come to their dwellings so they would help me. They have helped me in buying groceries during the last few months." (Participant C3) "None of my family members associate with me since I got married without their consent. But during the last few years I visit a sister's house during vacations." (Participant C2)

Regardless of the past, most of them admitted to the fact that they prefer having a positive relationship with their families.

Family of In-Laws- Based on the analysis, four of the widowed and divorced mothers agreed to have a stronger relationship with their in-laws, while the other two stated that it became weaker after becoming a single mother. Most of the in-laws were on good terms with the children. However, the relationship of widowed mothers to their in-laws was impacted by additional factors such as the age of the in-laws and the economic status of both parties.

"My in-laws are quite old and are in a situation of seeking the help of others. And I am not in a 
condition to help them. There are other children of them to look after them. I was in a good relationship with them before my husband's death." (Participant A1)

All of the separated mothers were not on good terms with their in-laws after being separated. A common factor all of them demonstrated was that their inlaw's family was the major cause for the separation. The husbands of these single mothers were said to be either in a relationship, willing to get into another relationship, or married to some other women. And they stated that the in-laws were supportive of the husbands in all their wrongdoings.

"They know everything about me and they know that their son was doing something wrong. Although they realize he does wrong because of their love they are not giving up on their son or brother. But I know that he can hide his faults to anyone but not God." (Participant C1)

"They hated me all the time because my husband took good care of me at the beginning of our married life. His sisters are the ones who made him get married again. I don't talk to any of them now." (Participant C3)

Friends- According to the discussion, one widowed mother has never had friends while the other two stated that they had many friends before marriage. Their relationship with the friends became weaker after marriage since they had the duty of a wife and mother. Although they have friends at present, they have always made sure to prevent sharing their personal information.

"But I don't share my personal information with anyone." (Participant A3)

The divorced mothers' views corresponded with the above where they ensured to prevent sharing their personal information. Hence, a predominant factor to be mentioned was that despite having friends before marriage, the divorced mothers had found barriers from the family of in-laws or the partner in maintaining a relationship with the friends.
"But after the marriage, communicating with my mother over the telephone itself is a huge challenge because my in-laws never liked me having a conversation with anyone. Due to this, I lost my relationship with many friends." (Participant B2)

"After marriage, my friends tried to contact me and my husband refused. He was controlling and possessive." (Participant B3)

Moreover, a contradictory view was derived from separated mothers where all of them mentioned that they had no relationship with the friends after getting married and it remains the same till present.

Neighbors- Based on the discussion, two of the widowed mothers stated that their relationship with the neighbors remained the same before and after single motherhood. One of them stated that she was ignored by some of them and they never inquired about the well-being of her family.

"When he was alive I had a good relationship with my neighbors. But once he passed away, some avoided us." (Participant A1)

Moreover, one among the three divorced mothers demonstrated that she had a constructive relationship with the neighbors. Hence, it was crucial to acknowledge the fact that she got divorced based on the husband's preference. Unlike the above participant, the other two had got divorced based on their own preference and they revealed that they avoided having a relationship with neighbors especially because they never wanted to answer their queries.

"I didn't associate much with them after getting divorced because I didn't want to answer their questions." (Participant B3)

However, the separated mothers seemed to have a disparity in relation to the neighbors based on the dwelling prior to and post single motherhood. The two mothers who stated that their relationship with them remained the same lived in their own house. But, the other one who stated that her relationship with the neighbors is on bad terms lived in a rented 
house after her husband's separation. She found it awful to tolerate them except for a few.

"There are some neighbors who help us. But some spread rumors about us. There is a family near our house who helps me in times of emergency. But the others spread rumors saying men visit our home or hide in our home. I am fed-up with this life. They are the ones who hurt me when I try to make up my mind to lead our life." (Participant C2)

\section{The difference in comparison to the status prior and post single motherhood}

Based on the analysis, all the widowed mothers stated that their status heightened as a single mother with the sole responsibility of children. However, a minor distinction can be identified with the reasons provided by each category of single mothers. For the widowed mothers, their status was heightened as they possess a shared responsibility of being a mother and a father abruptly without their willingness while a minute frustration was demonstrated via the conversation. They revealed it with the fact that their husbands had a huge responsibility for the children while the role was suddenly imposed on them as an addition.

"I think my status as a mother is uplifted in being a single mother because $I$, as a sole parent am responsible for my son. Earlier, my husband used to take a huge responsibility. My responsibility is overloaded as a single mother." (Participant A3)

One divorced mother stated that her status was the same as being a mother as well as a single mother since she had raised the child by herself since birth. Besides the fact of identifying their status to be heightened in single motherhood, the other two mothers demonstrated a certain sense of independence and maturity they had achieved in life.

"I wasn't matured enough then. But I think I am a strong mother now." (Participant B2)

"I feel constant freedom in being a single mother. I sought much attention from my husband. I learned the ultimate lesson of not seeking attention from anyone. I teach that to my child too." (Participant B3) Moreover, among the discussion of three separated mothers one agreed that her status was heightened, one stated that her status was the same while the other expressed that she hadn't realized or examined her status. "During all the time my only aim was to live for my kids." (Participant C1)

\section{Their perspective on society's views and stereotypes about single mothers}

Based on the results, all single mothers had the opinion that society had always identified or labeled them negatively. Many of them directly stated that certain negative stereotypes are completely wrong. However, the results of the discussion with widowed mothers showed the presence of certain pain due to the abrupt change of their lives after the partner's demise. There seemed to be a feeling of yearning where they expect society to acknowledge their pain and hardships.

"I think the time should teach the others about what we are going through in our lives." (Participant A1)

"The society blames us as if there is no probability of them attaining a life similar to ourselves. They do not think of how it will be for them if we are their mother, daughter, sister, or any other close relative." (Participant A2)

A minor distinction can be noticed among the three divorced mothers in their views about society's perspectives. The mother who was divorced by the partner stated that she was not directly addressed or accused by society but often encountered them indirectly.

"I myself have experienced the same when I was kept away from getting involved in a function by my neighbor. They did so because I being a single woman without a husband and therefore can't engage in rituals of any gracious occasions. Although they did not directly communicate the fact, I felt it." (Participant B1) 
The two divorced mothers who got divorced based on their personal preference claimed that they were often accused directly. A predominant factor to be notified in the discussion was that these mothers were nervous about being questioned about their personal life maybe because there is a tendency to be blamed frequently.

"The society looks down upon us thinking divorce is a minus in our life. Without knowing the actual situation, we are blamed." (Participant B2)

"Especially, females in our society have these views. And I would like to say that I am still afraid of them." (Participant B3)

The three separated mothers had similar views like the above that society often expresses negative views about single mothers. They implied that the major reason for them not getting divorced was that they prefer not to be blamed by society and prove the presence of a husband as a source of defense. According to them, the mere presence of a husband itself was adequate to stay away from society's negative opinions rather than being a divorced mother.

"When a single mother goes out of the house, the whole crowd looks at her." (Participant C1)

"I think there is a huge difference in how society treats a mother and a single mother." (Participant C3) However, the overall results of the discussion demonstrated that all of the single mothers had the opinion that they were at higher risk of being blamed and labeled in society compared to the partnered mothers.

\section{Single Mother's view on how she is regarded}

The particular theme was discussed to inquire from the participants regarding a single mother's idea of how she was looked at by society. It was a major aspect to acknowledge that most of them had a similar opinion. The common consideration of two single mothers was that there is a presence of lagging in fulfilling their needs and their family's for the fear of being blamed or labeled.
"I think time should teach others about what we are going through in our lives. Because I cannot put astray my children for the sake of being a single mother. I have to fulfill their duties alone in society." (Participant A1)

"I go out to get medicine for my mother, to my children's school, to buy groceries. I don't behave in such a way to be blamed by society." (Participant C1) Moreover, another factor that two of the single mothers mentioned was that they identify the society being sympathetic about them. Most of the time they felt it to be something negative and hurtful for themselves as well as their children. They mentioned further, that the mere absence of a husband to themselves and a father to their children was a predominant factor for the sympathy of society. Hence, both of them agreed that they refused this sort of emotion towards them.

"Therefore, I try my best not to show my weakness but portray myself to be a strong woman, which is an advantage. And I feel safe via this." (Participant A2)

"And such expressions are unbearable." (Participant B1)

Two single mothers stated that there was a tendency for them to lag behind in gatherings as well as encountering society. Further, they clarified that they were anxious to answer society's questions about their personal life. They firmly stated that their family had always supported and pushed them forward when they felt low and stayed backward.

"Although my family members do not hurt me with any behaviors, I have the fear of being labeled or accused. If I try to be aside during gatherings, my family always push me forward to engage in all type of rituals." (Participant A3)

"I don't attend functions or occasions without of the family." (Participant B2)

Three other single mothers stated the presence of a high probability of risk in being victimized by society for their behaviors. A divorced mother revealed an incident which had occurred when she was a teacher 
in a school, where a co-teacher who was a father of many children sought her help as she was fluent in the English language. This incident had led to a huge issue where his wife had come to the school and blamed her for trying to take to her husband. She further mentioned that she stopped talking to him afterward. A separated mother disclosed how they become vulnerable to abuse for the reason of living without a husband's presence (Karunanayake, Jayasundara \& Vimukthi, 2020).

"Sometimes I get unknown calls and stuff. And that is the reason for me to not get divorced. Society will look at a woman living with a partner, not with a bad eye but looks at women living without a husband with bad eyes even if she gets a call which might be an important call for her." (Participant C3)

It was significant that most single mothers experience negative consequences frequently by society in comparison to partnered mothers.

\section{Satisfaction with their present life}

The current theme was discussed with the participants to identify whether they prefer the present life compared to the past and the reasons for their answer. A major concern to be notified was that the widowed mothers found their past life to be much more satisfied compared to the life of being a single mother. Despite their attempts to live the present life normally, they found the memories of past life and their children's satisfaction to be the major reason for living in the present.

"I find it really difficult to get adapted to this life without a husband and I can never forget my husband. I am living my life only for the sake of my son and my mother." (Participant A3)

However, all of the divorced mothers stated that their present life was satisfactory compared to the past. The major reason for their view was that they had been in an unstable life full of conflicts during the past. Currently, they lead a satisfying life with independence and freedom.
"There was no space or hope for my wishes and likes when I was with him. Not even ten percent of space was available for my wishes with him." (Participant B1)

"Staying with a husband and living a peaceful life are two different things. I think living a peaceful life is much more important. The only missing factor is the absence of a partner. But it does not impact me." (Participant B2)

"Today I have the ultimate freedom." (Participant B3)

The overall view of the divorced mothers seemed to be that they feel relieved and satisfied with the present life besides the fact of living without a partner. The three separated mothers demonstrated different opinions about their present life. One of them stated that she preferred being single than living with a wrong partner and that she feels satisfied with the present life. The other two mothers stated that they preferred their past life and that their present life was not satisfactory at all.

"I am mentally down. And I always think that the life I am leading now is the result of a wrong marriage." (Participant C2)

"I was a hundred percent happy living a life with my husband." (Participant C3)

However, the overall conversation demonstrated that the satisfaction to the life of single mothers depended on their sense of acceptance and the courage to encounter society.

\section{Ideologies about autonomy in women (prior and past single motherhood)}

The present theme was based on the views of the single mothers about autonomy in women while being a partnered mother and after becoming a single mother. The discussion centered on the context of their ideology about gaining an education and engaging in an occupation. It was important to state that most of them had never thought about engaging in an occupation or acquiring any type of education after marriage or during their stay as a partnered mother. 
"Earlier I had the mindset that I don't need to engage in any occupation but live as a housewife." (Participant B1)

Two of them stated that the idea of autonomy bloomed after their marriage and when they found themselves to be miserable and dependent on the partner.

"And I understood that I would not have been thrown out of the family if I have had a good education and an occupation." (Participant B2)

Nevertheless, the current view of all the single mothers was similar where they stated the importance of autonomy for a woman whether single or a partnered mother.

"It should be present while the husband was alive too so that a demise will not impact much in the lives later." (Participant A1)

"But now I think that it is important that women do learn and engage in some sort of occupation. If I had learned something then, I would have been better now." (Participant B3)

\section{Future expectations of single mothers}

The following theme focused on identifying the expectations of single mothers and how they think they should be treated by society. Five single mothers shared a similar view that even if society does not aid them economically they should not blame them psychologically. They stated that being accused of all the activities and the tendency of being victimized to be the major causes of becoming psychologically hurt. "It does not matter whether they can help us or not. But they should try their best to let us live in peace without hurting us. They should at least understand how much pain we undergo mentally and physically leading this life." (Participant B2)

"If I don't go seeking help from the others, and I and my kids don't bother the others, there is no need for the others to look into my life." (Participant C3)

Three of the single mothers suggested that certain awareness and developmental programs can be conducted to guide and aid single mothers psychologically in society.

"Programs can be conducted to single mothers in guidance. This can prevent them from going towards the wrong solutions. I have also seen such mothers showing their frustration towards the kids. Respecting our emotions can be better." (Participant A1)

"There are many programs for couples to prevent breaking the marriage. But there aren't any programs for these types of issues. Even if they need help, they should seek a counselor by themselves and there isn't any awareness provided to them." (Participant A3)

Moreover, a major suggestion of a widowed mother was that society should come forward to making a life for these single mothers by helping them remarry. She also complained that most of them communicate regarding this matter but none of them exert an effort to make them come true. Another major concern was about remarriages with the responsibility of children. "Even when these women agree to remarry, most men do not prefer marrying them with the responsibility of the children. And again the society blames this single mother for not willing to leave the kids." (Participant A2)

Moreover, the ultimate result of the theme demonstrated by all the single mothers was that society should understand that the life of a single mother is not easy and that they can support them psychologically by refraining from spreading rumors around.

"The society should understand that we have a heart and feelings. And they should also comprehend that we have a huge financial crisis. Even if they don't help us financially, they can stay silent without spreading rumors." (Participant A3)

The information gathered from the interviews were thematically analyzed in order in the section above giving comprehensive meaning to the results section. Each theme was given substance via the quotes of the participants presented during the interview. This 
chapter will provide the background for the discussion that follows next.

\section{DISCUSSION}

\section{Demographic Details}

The nine single mothers who participated in the study were interviewed based on the categories of being a widow, a divorcee, or a separated mother who was responsible for school-age children. Most of them had married in their twenties or early thirties and are currently in their thirties. According to the information provided, all the divorced mothers had one child and they had got divorced when the child was at a young age. The separated mothers had more than one child and they do not prefer getting divorced. The divorced mothers had a scheduled form of life with their child while the separated ones were in a dilemma of being unable to plan the future.

The major reason behind this dilemma can be that most of them had the label of being someone's wife and that it might provide a sense of security or a shield of protection for their lifestyle. Based on the cultural context, most parents prefer their daughters to get married to a partner and in the cluster of marriage, education, occupation, personal preference, etc., it has become a priority. In the current situation, none of the participants had engaged in higher studies or any occupations that had an academic component. Most of them engage in self-employment and some do not engage in any employment.

Encountering society in leaving home was a major concern for most of them and the sole responsibility of the children was one of the barriers to engaging in an occupation (Karunanayake \& Vimukthi, 2020). Moreover, most of the single mothers and their families tend to live with their parents if they were alive. Living in their own house or a rented house impacts their well-being differently because the single mothers who live in rented houses felt insecure about the future. The impermanency of the dwelling can be an additional load to the financial struggles along with the sole responsibility of children.

\section{Major Challenges}

The Responsibility of Children- One of the major responsibilities of single mothers was the responsibility of children. Based on the traditional family system, a mother has a set of responsibilities towards a child while a father has a different set of responsibilities. Being a father as well as a mother to the children is a greater load to the sole parent. Besides maintaining the financial aspects of the family, a father is identified as a guardian to the family. A single mother household lacks the protection of a father especially in the presence of female children. A major concern for single mothers with male children is the absence of a parent who can be a role model and a person to control their son (Karunanayake, 2000; Karunanayake \& Nauta, 2004).

The following aspect is similar to the findings of the research conducted on the Problems Faced by Single mothers by Kotwal and Prabhakar (2020) which emphasized that the single mothers demonstrated difficulty in maintaining discipline and lay routine among the children. It is important to acknowledge that most single mothers feel nervous to leave their house whatever the cause is, which makes them more vulnerable in fulfilling the needs of their families.

Financial Crisis- Based on the expectations of society, the father is provided with the role of managing the financial needs of a family. Hence, a single mother family may encounter the struggles of the financial crisis at any point in their lives. Almost all of the participants in the study emphasized it to be a major challenge in leading their lives. It is important to notice that single mothers identify the management of finances in the family to be a significant stressor where their priority of concern is to fulfill the needs of their children. 
A study conducted by Stack \& Meredith, (2018) reveals that the major challenge of single-parenting is the poverty and non-availability of service providers and the lack of resources. The crisis seems to be highly destructive in the case of living in a rented dwelling. The non-availability of a permanent dwelling is an added disadvantage for the single mother family due to the lack of shelter and security.

Confronting the Society- The concept of single motherhood is often considered to be a stigma in society. The mothers who are divorced are more vulnerable than widowed or separated. A similar view is demonstrated in a study that states that single mothers encounter certain social challenges such as discrimination, task overload, stigmatization, stereotyping, and insecurity (Wangechi Watuthu et al., 2017). The very factor of "how will I face the society" itself is a major challenge to the single mothers since they are at risk of being blamed in comparison to the partnered mothers.

Lack of Emotional Dependence- Single mothers tend to live a life within themselves and prevent conversations with society to avoid sharing their emotions. This is more prevalent among the widowed mothers whose loss of the partner is sudden or unexpected. The emotional dependence she had on the husband is quite hard to be transferred to another individual. Despite dwelling with parents and children, they tend to have less dependency on them or the others in society.

\section{Economic Well-being of the Family}

Maintaining economic well-being was considered to be the major challenge for single mothers (Kotwal \& Prabhakar, 2009). Widowed mothers often rely upon their family, especially their parents to manage the financial well-being of the family. Hence, it is evident that they are pretty sure of not being a burden to their family. However, divorced mothers have the option of receiving child maintenance money for their children. Most of the divorced mothers tend to lead their life with that allowance provided to the children. And maybe due to society's stereotypes or their personal preference, most of them prefer not to engage in any occupation outside their home. This is a major reason for single mothers to engage in selfemployment at home.

\section{The prior and post relationship of Single Motherhood}

Children- According to society, being a mother is often to take care of the children, providing them warmth and love, making the best of what the partner earns to fulfill the needs of children. Being imposed with half of the responsibility and taking up the complete responsibility of the family are two different concerns. Most of the widowed mothers are abruptly imposed with the sole responsibility of children and the family. Therefore, their relationship to the children as a mother and a single mother is considered to be a heavy load.

Her family - The relationship of the single mothers with her family and her husband's family is often alike since most single mothers seek the attention of their family after becoming single. The relationship of the widowed mothers to their family seemed to be quite distinct because most of them seldom relied on their parents after marriage. The sudden shift of dependency on the family is often demonstrated to be a strenuous task. The divorced mothers frequently are dependent upon her family during the crisis after marriage and it is her parents who get involved mostly during the process of getting divorced. The result of their future is quite visible and her family is already alarmed. This situation is quite contrary to the widowed mothers, whose change of lives is unpredictable and abrupt. The separated mothers are somewhat in between the widowed and the divorced mothers where they live in a neutral relationship with their family and the husband's family.

Family of In-Laws- The single mothers of different causes have distinct relationships with their in-laws. Most of the widowed mothers tend to be on good terms after the husband's demise, especially in terms 
of children. The separated mothers are often on bad terms with their in-laws after becoming single since their major concern about the present status is that the in-laws support their son. However, the divorced mothers tend to be in-between widowed and the separated ones where their relationship is either strong or weak depending on the type of separation.

Friends- In general, a woman's life and relationship change immensely after marriage. The impact is quite noticeable even in the relationship with their parents. Therefore, a certain extent of distance is anyway present with friends mostly due to the responsibilities of new relationships at the in-laws. Most single mothers do not prefer sharing their personal feelings with anyone including friends and the family.

Neighbors- The relationship of the single mothers with their neighbors is quite different among the categories of mothers. The neighbors are considered to be more or less a representation of the society which every individual has to encounter. Most widowed mothers have a similar relationship with the neighbors as their lives seen to be designed by God and destiny. Divorced mothers tend to have a hard time accepting divorce and their contribution to it. A high proportion of divorced mothers tend to have less or no acquaintance with the neighbors for the fear of answering their questions. However, the separated mothers' relationship depends on their dwelling past and prior to single motherhood. Most single mothers who live in the same place tend to have a similar relationship while the ones who shift to a new dwelling often tend to be in an awkward situation in building up relationships. The relationship between the single mothers and the neighbors depend on society's acceptance and ideologies about single motherhood.

\section{The difference in comparison to the status prior and post single motherhood}

Being a mother itself increases the status of women: in bearing a child, giving birth, feeding, and providing love and warmth while raising them.
Becoming a single mother is a double upswing of the status where they become the father as well as the mother to the children. Besides the increase of status, the acceptance of single motherhood is quite distinct among each of the categories. The widowed mothers often accept single motherhood without prior notice and therefore it becomes an abrupt change in their lives. Therefore, they examine the adoption of this change as a heightening process of their status. Most divorced mothers tend to live literally as a single mother even during the presence of a partner, which usually becomes the major cause of divorce. Besides the fact of being divorced by their personal opinion or due to the partner, they tend to adapt to the life of single motherhood better. The probability of acceptance of single motherhood is often quite higher in divorced mothers compared to widowed and separated mothers. They tend to equate divorce to an improvement of freedom and responsibility in their current life. The identification of status among separated mothers depends mostly on the cause of separation and the current life they lead.

\section{Their perspective on society's views and stereotypes about single mothers}

Single motherhood is often identified differently in society. The woman without a male guardian whether she is the daughter of a father or a wife of a husband is treated differently in comparison to the other women with a male guardian. It is quite visible in those families where they often become vulnerable to the accusations and threats from society. They are regarded to deserve sympathy on the other hand on certain occasions. This eventually leads the singlemother families to stay away from society. According to Stack \& Meredith, (2018) the single-parent families' social functioning was affected negatively due to the social isolation that these families encounter. Besides the obvious context, there seems to be a different perspective from the view of the single mothers about the negative ideologies and stereotypes of society. The widowed mothers tend to view the society to look 
upon them in both sympathetic as well as labeling manners. There seems to be a yearning among them for society to acknowledge their loss and appreciate their adaption to the abrupt change in their lives. The divorced mothers tend to receive either direct or indirect accusations based on either their own preference or the partner's wish to get divorced. The ones who seek divorce on their personal preference tend to be blamed directly while the others indirectly by society. However, the separated mothers' major concern is to prevent a divorce, where they tend to have confidence that they can stay away from being blamed by society at least by the mere presence of a husband in spite of him not having any relationship to the family. Even without the husband providing financial aid, security, love, and warmth, the significant aspect is that a woman may survive with the mere presence of a partner which often seems to be a defense from the negative views and stereotypes of society.

\section{Single Mother's view on how she is regarded}

According to the results of the interviews, the major concerns of these single mothers were the fear of engaging in places outside their home, being sympathized by others, being nervous in attending public occasions, and being vulnerable to abuses from society. The following view is quite similar to the findings of the study held in Kiambu country, Kenya which stated that single mothers encounter discrimination, task overload, stigmatization, stereotyping, and insecurity from the society (Youngblut, Brady, Brooten, \& Thomas, 2000). Despite the fact of repeated occurrence of such instances, the single mothers are quite thoughtful about these accusations and of being stigmatized by society. This thought is often inbuilt in their thoughts which might frequently become a hindrance to their daily routine of life. The idea of prevention from attending instances of meeting the society was demonstrated by Kotwal \& Prabhakar (2009) in their study on Problems faced by Single Mothers which reveals that in addition to the above factor, they also had adapted to change their way of dressings, food as well as eating habits (Karunanayake, Jayasooriya \& Vimukthi, 2020).

\section{Satisfaction with their present life}

The single mothers' like for the present life often depends on the acceptance and the strength to overcome the challenges of life. Most of the widowed mothers find their past life in the presence of their husband to be more satisfactory than the present life. The major reason for this fact can be that they tend to live a partnered life in the past while the status of becoming single is usually abrupt. The majority of them are on good terms and preference for their partners. In a study conducted in Trichy District where most of the participants were widowed mothers, a majority (90\%) were not happy with their current life (Rebecca et. al., 2002). Another study states that the women of single-parent families tend to have a lower quality of life, lower-income, and greater depression in comparison to the women of partnered families (Hernández et al., 2009).

However, the divorced mothers contrary to the widowed stated that they were satisfied with the present life in comparison to the past. The major concern about the divorced mothers is that their separation is based on a pre-informed alarm which is either the partners' or their personal preference. They acknowledge that their life will not continue with the same individual and tend to get adapted to the present life. Most of them find their present to be more satisfactory than the past since their whole or the final part of being a married woman was of conflicts and disagreements.

The separated mothers' ideologies of satisfaction are based on their acceptance and courage to encounter their life without a partner. The ones who expect their husbands to rejoin might find the past to be pleasant and prefer satisfaction in the future with the reunion. The ones who will deny the reunion might 
find the present to be more satisfactory. A similar view is demonstrated in a past study which states that when single-parents feel united and welcomed in their society it makes them have greater satisfaction (Al Qallaf, 2018).

\section{Ideologies about autonomy in women (prior and past to single motherhood)}

The majority of the single mothers in this study have not engaged in higher studies and none of them had been employed after marriage. However, some of them revealed that they preferred engaging in an occupation after marriage when they found themselves to be dependent upon the partner. It is quite obvious that most mothers do not have an idea about studies or engaging in any type of job until they become desperate or in need of solving their economic crisis. But, in some contexts, the autonomy itself might lead to conflicts among the partners. Past research based on the divorced mothers show that the women's employment facilitates marital disruption in countries of Italy and Poland, but not in Germany and Hungary (Vignoli, Matysiak, Styrc \& Tocchioni, 2018).

A study states that the present employment of single mothers enhances their mental health depending on the stability of employment and its being long term (Zabkiewicz, 2010). This result is correspondent to the view of the participants who prefer having a stable occupation for the long term run of their life.

\section{Future expectations of single mothers.}

Despite the cause of single motherhood, they want to have the independence to lead their life with their children. Most single women are vulnerable to be accused and abused by society and hence their predominant expectation is that society does not harm them psychologically. They further expect society to help them remarry where their children can live under their care and protection and are not asked to stay away. The majority of single women often refuse remarriage for the fear of losing their children in the process. This view is quite similar to the results of a study which states that there is somewhat greater acceptance of single mothers than single fathers, and women are more accepting than men of a single mother (Goldscheider \& Kaufman, 2006). Another frequent expectation seems to be the need for conducting awareness programs and receiving aid from the government. The ultimate expectation of most single mothers seems to be that "let us live our lives".

\section{CONCLUSION}

The study was conducted with the main purpose of identifying the psychological well-being of singleparents in relation to the major challenges, economic well-being, and relationships with the family and the society, their ideologies about the current status, the society's stereotypes, their satisfaction, their views about autonomy and their future expectations. The study demonstrated that besides the cause of single motherhood, most of them found something to be missing in their lives at least in the context of having a male guardian to their children. The single mothers revealed the responsibility of their children and the financial crisis to be the major challenges of single motherhood. The study further disclosed the importance of autonomy in women to adapt to the changes in life. Moreover, the research demonstrated the underlying pain of the single mothers in surviving in the society with the stereotypes they face and their yearning for society to acknowledge their sufferings in being a single mother.

\section{REFERENCES}

[1]. Hossain, F. and Ali, M. (2014) Relation between Individual and Society. Open Journal of Social Sciences, $\quad 2, \quad 130-137 . \quad$ doi: 10.4236/jss.2014.28019. 
[2]. Rosenthal, C., \& Marshall, V. (1986). The Head of the Family: Social Meaning and Structural Variability. The Canadian Journal of Sociology / Cahiers Canadiens De Sociologie, 11(2), 183198. Doi:10.2307/3340797

[3]. Young, I. (1995). Mothers, Citizenship, and Independence: A Critique of Pure Family Values. Ethics, 105(3), 535-556. Retrieved December 27, 2020, from http://www.jstor.org/stable/2382141

[4]. Williams B. Carey, William L. Coleman, Heidi M. Feldman, Allen C. Crocker, Ellen Roy Elias. Developmental-Behavioral pediatric (2009). Saunders. ISBN 978-1-4160- 3370-7, DOI: https://doi.org/10.101.6/B978-1-4160-33707.X0001-6

[5]. Smolka, A. (2001). That's the Ticket: A New Way of Defining Family. Cornell Journal Of Law And Public Policy, 10(03).

[6]. Biblarz, T., \& Gottainer, G. (2000). Family Structure and Children's Success: A Comparison of Widowed and Divorced Single-Mother Families. Journal of Marriage and Family, 62(2), 533-548. Retrieved December 27, 2020, from http://www.jstor.org/stable/1566757

[7]. Goldscheider, F., Scott, M. E., Lilja, E., \& Bronte-Tinkew, J. (2015). Becoming a Single Parent: The Role of Father and Mother Characteristics. Journal of Family Issues, 36(12), 1624-1650.

https://doi.org/10.1177/0192513X13508405

[8]. Williams, R., \& E. Compas, B. (1988). Stress and Psychological Symptoms in Single and Dual Parent Families.

[9]. Li, Q. (2020). Mothers Left Without a Man: Poverty and Single-parenthood in China. Cogitatio, 08(02), 114-122. 68

[10]. Hernández, R., Aranda, B., \& Ramírez, M. (2009). Depression and Quality of Life for Women in Single-parent and Nuclear Families. The Spanish Journal Of Psychology, 12(1), 171-
183.

https://doi.org/10.1017/s113874160000158x

[11]. Lee MY, Law CK, Tam KK. 1999. Parenthood and life satisfaction: a comparison of single- and dual-parent families in Hong Kong. International Social Work42(2): 139162 (3) (PDF) Spaces of silence: Single parenthood and the 'normal family' in Singapore. Available from: https:/www.researchgate.net/ publication/230014515_Spaces_of_silence_Singl e_parenthood_and_the_'normal_family'_in_Sin gapore [accessed Dec 28 2020].

[12]. Gotea, M., \& Busuioc, M. (2016). Maternal Single-Parent Family in Social Risk Situation. Psychosocial and Behavioral Characteristics. Bulletin Of The Transilvania University Of Braşov, Vol. 9 (58) (No. 1).

[13]. Quinn, P., \& Allen, K. (1987). First Hand Lessons in an Information Age: Single-parent Working Women Speak for Themselves. National Council On Family Relations. A.

[14]. William T, B. (1975). The Single-parent Family: Some'Social and Psychological Characteristics and Their Implication for Social Policy Decisions. Paper Presented At The Annual Meeting Of The American Educational Research Association.

[15]. Stack, R. J., \& Meredith, A. (2018). The Impact of Financial Hardship on Single Parents: An Exploration of the Journey From Social Distress to Seeking Help. Journal of family and economic issues, 39(2), 233-242. https://doi.org/10.1007/s10834-017-9551-6

[16]. Samuels-Dennis, J. (2007). Employment Status, Depressive Symptoms, and the Mediating/Moderating Effects of Single Mothers' Coping Repertoire. Public Health Nursing, 24(6), 491-502. https://doi.org/10.1111/j.15251446.2007.00661.x 
[17]. Hammans, L. (2010). Poverty and Psychological Well-being in Single, Low- Income Mothers: A Meta-Analysis.

[18]. Mulroy, E., \& S. Lane, T. (1992). Housing Affordability, Stress And Single Mothers: Pathway To Homelessness. The Journal Of Sociology \& Social Welfare, 19(3). Retrieved 14 June 2020, from https://scholarworks.wmich.edu/jssw/vol19/iss3 $/ 4$.

[19]. Ahmad, N., Alavi, D., Che Kasim, D., \& Sheau Tsuey, D. (2015). Psychological Well-being among Single Mothers of Rural and Urban Areas in Selangor. International Journal Of Technical Research And Applications, 23208163(25), 43-46. Retrieved 14 June 2020, from http://www.ijtra.com.

[20]. Segal-Engelchin, D., \& Wozner, Y. (2005). Quality of Life of Single Mothers by Choice in Israel: A Comparison to Divorced Mothers and Married Mothers. Marriage \& Family Review, 37(4), 7-28. https://doi.org/10.1300/j002v37n04_02

[21]. Abd Ghani, F., Ibrahim, F., Abd Aziz, A., \& Mahfar, M. (2015). Relationship between the Belief System and Emotional Well-Being of Single Mothers. Asian Social Science, 11(27), 28. https://doi.org/10.5539/ass.v11n27p28

[22]. Ifcher, J., \& Zarghamee, H. (2010). Trends in the Happiness of Single Mothers: Evidence from the General Social Survey. SSRN Electronic Journal. https://doi.org/10.2139/ssrn.1740029

[23]. Zekeri, A. (2020). Household Food Insecurity and Depression among Single Mothers in rural Alabama. Journal Of Rural Social Sciences, 25(1), 90-102.

[24]. Weldegabreal, R. (2014). A Qualitative Study on Single mothers' Experience of Raising their Dependent Children: A case in the Lideta Sub City of Addis Ababa.
[25]. Tucker, M., \& Kelley, M. (2009). Social Support and Life Stress as Related to the Psychological Distress of Single Enlisted Navy Mothers. Military Psychology, 21(sup2), S82-S97. https://doi.org/10.1080/08995600903249198

[26]. Wangechi Watuthu, M., Kaaria, D., \& Wamalwa, D. (2017). Psychosocial Challenges Affecting Parenting Among Single-parents in Ndumberi Zone, Kiambu Country, Kenya. Academic Journal Of Social Sciences And Education, 10(03), 101-137.

[27]. Subramaniam, M., Omkar Prasad, R., Abdin, E., \& Ajit Vaingankar, J. (2014). Single Mothers Have a Higher Risk of Mood Disorders. Annals Academy Of Medicine, 43(3), 145-151. Kotwal, N., \& Prabhakar, B. (2009). Problems Faced by Single Mothers. J Soc Sic, 21(3).

[28]. Karunanayake, D., \& Vimukthi, N.D.U. (2020). Preschool children's occupational expectations and its relation to their perception of gendertyped occupations. International journal of advanced research and review. IJARR, 5(10), 2020; 32-39

[29]. Karunanayake, D., Jayasundara. N., \& Vimukthi. N.D.U. "The Impact of Sex Work on Psychological Wellbeing", International Journal of Scientific Research in Science and Technology (IJSRST), Online ISSN: 2395-602X, Print ISSN: 2395-6011, Volume 7 Issue 5, pp. 180-190, September-October 2020. Available at doi: https://doi.org/10.32628/IJSRST207533 Journal URL: http://ijsrst.com/IJSRST207533

[30]. Karunanayake, D., Amarathunga, T.P.N.K., \& Vimukthi, N.D.U. (2020). Girls' academic performance: single sex schools versus coeducational schools. International journal of advanced research and review. IJARR, 5(11), 2020; 43-53

[31]. Karunanayake, D., Bambarawana, D.T., and Vimukthi, N.D.U. (2020). The relationship between childhood Experiences and Later 
Appearance of Drug Addiction. International Journal of Indian Psychology, 8(4), 50-55. DIP:18.01.030/20200804, DOI:10.25215/0804.030

[32]. Karunanayake, D. (2000). A comparison of role model influence between Caucasian and Minority College students in making academic and career decisions. Unpublished Masters thesis, Illinois State University, Normal, IL, USA.

[33]. Karunanayake, D., \& Nauta, M. M. (2004). The relationship between race and students' identified career role models and perceived role model influence. The Career Development Quarterly, 52(3), 225-234.

[34]. Kotwal, N., \& Prabhakar, B., (2009) Problems Faced by Single Mothers, Journal of Social Sciences, $\quad 21: 3, \quad 197-204, \quad$ DOI: 10.1080/09718923.2009.11892771

[35]. Youngblut, J. M., Brady, N. R., Brooten, D., \& Thomas, D. J. (2000). Factors influencing single mother's employment status. Health care for women international, 21(2), 125-136. https://doi.org/10.1080/073993300245357

[36]. Karunanayake, D., Jayasooriya, M. W. D. S. M., \& Vimukthi, N. D. U. (2020). Psychological Impact on the Eating Behaviors of University Students. South Asian Journal of Social Studies and Economics, 8(4), 132-141. https://doi.org/10.9734/sajsse/2020/v8i430225

[37]. Rebecca L. Utz, MGS, Deborah Carr, Ph.D., Randolph Nesse, MD, Ph.D., Camille B. Wortman, Ph.D., The Effect of Widowhood on Older Adults' Social Participation: An Evaluation of Activity, Disengagement, and Continuity Theories, The Gerontologist, Volume 42, Issue 4, 1 August 2002, Pages 522533, https://doi.org/10.1093/geront/42.4.522

[38]. Al Qallaf, J. (2018). Exploring The Influence of The Background Factors on Well-being of
Single-parents in Kuwait: A Structural Equation Modeling Approach.

[39]. Vignoli, D., Matysiak, A., Styrc, M., \& Tocchioni, V. (2018). The positive impact of women's employment on divorce: Context, selection, or anticipation?, 38(37), 1059-1110. doi: 10.4054/DemRes.2018.38.5

[40]. Zabkiewicz, D. (2010). The mental health benefits of work: do they apply to poor single mothers?. Psychiat Epidemiol, 45, 77-87. doi: 10.1007/s00127-009-0044-2

[41]. Goldscheider, F., \& Kaufman, G. (2006). Singleparenthood and the Double Standard. Research Gate. doi: 10.3149/fth.0402.191 Lee, M., Law, C., \& Tam, K. (1999). Parenthood and life satisfaction. International Social Work, 42(2), 139-162. doi: 10.1177/002087289904200204

\section{Cite this article as :}

Dr. D. D. K. S. Karunanayake, Mohamed Nazeer Aysha, N. D. U. Vimukthi, "The Psychological WellBeing of Single Mothers with School age Children : An Exploratory Study", International Journal of Scientific Research in Science and Technology (IJSRST), Online ISSN : 2395-602X, Print ISSN : 23956011, Volume 8 Issue 1, pp. 16-37, January-February 2021. Available at

doi : https://doi.org/10.32628/IJSRST21812

Journal URL : http://ijsrst.com/IJSRST21812 